\title{
Mental health effects of changes in psychosocial work characteristics: a prospective cohort study
}

Citation for published version (APA):

De Raeve, L., Vasse, R. M., Jansen, N. W. H., van den Brandt, P. A., \& Kant, Y. (2007). Mental health effects of changes in psychosocial work characteristics: a prospective cohort study. In The XIIIth European congress of work and organizational psychology https://doi.org/10.1097/JOM.0b013e31811eadd3

Document status and date:

Published: 01/01/2007

DOI:

10.1097/JOM.0b013e31811eadd3

Document Version:

Publisher's PDF, also known as Version of record

\section{Please check the document version of this publication:}

- A submitted manuscript is the version of the article upon submission and before peer-review. There can be important differences between the submitted version and the official published version of record.

People interested in the research are advised to contact the author for the final version of the publication, or visit the DOI to the publisher's website.

- The final author version and the galley proof are versions of the publication after peer review.

- The final published version features the final layout of the paper including the volume, issue and page numbers.

Link to publication

\footnotetext{
General rights rights.

- You may freely distribute the URL identifying the publication in the public portal. please follow below link for the End User Agreement:

www.umlib.nl/taverne-license

Take down policy

If you believe that this document breaches copyright please contact us at:

repository@maastrichtuniversity.nl

providing details and we will investigate your claim.
}

Copyright and moral rights for the publications made accessible in the public portal are retained by the authors and/or other copyright owners and it is a condition of accessing publications that users recognise and abide by the legal requirements associated with these

- Users may download and print one copy of any publication from the public portal for the purpose of private study or research.

- You may not further distribute the material or use it for any profit-making activity or commercial gain

If the publication is distributed under the terms of Article $25 \mathrm{fa}$ of the Dutch Copyright Act, indicated by the "Taverne" license above, 


\section{Mental Health Effects of Changes in Psychosocial Work Characteristics: A Prospective Cohort Study}

Lore De Raeve, MSc

Rineke M. Vasse, PhD

Nicole W. H. Jansen, PhD

Piet A. van den Brandt, PhD

\section{IJmert Kant, PhD}

Objective: To explore a possible causal relationship between psychosocial work characteristics and mental health. Methods: Using longitudinal data from the Maastricht Cohort Study on "Fatigue at Work" $(n=$ 2332), the effects of changes in job demands and decision latitude on subsequent changes in need for recovery and prolonged fatigue were studied. Results: Increasing job demands are a significant predictor of a subsequent increase in need for recovery $(\beta=0.063)$ and prolonged fatigue $(\beta=$ 0.057). An increase in decision latitude predicted a subsequent decrease in need for recovery $(\beta=-0.078)$ and prolonged fatigue $(\beta=-0.063)$. After adjusting for changes in other work characteristics, the effects on changes in prolonged fatigue were no longer significant. Conchusion: These findings support a possible causal relationship between work characteristics and mental health and can be used for designing effective prevention and intervention strategies. (J Occup Environ Med. 2007;49:890-899)
From the Departments of Epidemiology (Drs De Raeve, Jansen, van den Brandt, Kant) and Health Organization Policy and Economics (Dr Vasse), Maastricht University, Maastricht, The Netherlands. Address correspondence to: Lore De Raeve, MSc, Maastricht University, Department of Epidemiology, P.O. Box 616, 6200 MD Maastricht, The Netherlands; E-mail: lore.deraeve@epid.unimaas.nl. Copyright () 2007 by American College of Occupational and Environmental Medicine

DOI: 10.1097/JOM.0b013e31811eadd3 sychosocial work characteristics have previously been associated with a variety of adverse health effects, including cardiovascular health, ${ }^{1-3}$ musculoskeletal disorders, ${ }^{4-6}$ mental disorders, ${ }^{7-10}$ and fatigue, ${ }^{11-13}$ but also with poor self-reported health, ${ }^{14-16}$ sickness absence, ${ }^{17,18}$ and a number of behavioral risk factors. ${ }^{19-21}$ A leading conceptual model to describe the psychosocial work environment is the model described by Karasek. ${ }^{22}$ The initial model identifies two crucial components of the psychosocial work environment: job demands and job control (or decision latitude). Numerous studies have shown that both high job demands as well as low decision latitude are associated with adverse health outcomes. ${ }^{23,24}$ The majority of the studies examining the relationship between psychosocial work characteristics and mental health is based on a crosssectional design. ${ }^{25}$ Consequently no causal inferences can be drawn on the relationship between work characteristics and health. Some studies, however, did examine the prospective relationship between psychosocial work characteristics and mental health outcomes. A recent meta-analysis ${ }^{10}$ provides evidence that high demands and low decision latitude are prospective risk factors for common mental disorders and suggests that the psychosocial work environment is important for mental health. Despite their longitudinal design, previous prospective studies did not always 
succeed in disentangling the cause and effect relationship between psychosocial work characteristics and mental health. Two important methodological limitations, that is (1) the dynamic nature of the psychosocial work environment is not taken into account and (2) a change in the work environment was not measured before a change in mental health outcome, often prevent researchers from establishing a cause and effect relationship.

With respect to the first issue, existing longitudinal studies often use a so-called time lag model in which psychosocial work characteristics are modeled prior in time to the outcome variable. An important disadvantage of these studies is that they often ignore the rather dynamic nature of certain work characteristics. Only few previous studies have examined the relationship between changes in job demands and job control and changes in mental health outcomes. ${ }^{25}$ A study of Janssen and Nijhuis ${ }^{13}$ showed that a decrease in job demands and an increase in decision latitude were associated with decreases in fatigue, emotional exhaustion, and psychological distress. Another previous prospective study $^{26}$ found that increasing demands were associated with an increase in emotional exhaustion and that increases in aspects of job control (skill discretion and decision authority) were associated with a higher level of job satisfaction. Moreover, they also found evidence for a reversed effect of changes in health and well-being on changes in work conditions. The changes in work conditions and changes in health seemed to mutually influence each other. Another longitudinal study ${ }^{27}$ found that recent onset of job stress was strongly associated with the incidence of depression, anxiety, and chronic fatigue. Although these studies all applied a longitudinal design, the change in work characteristics was measured simultaneously with the change in the outcome measures, which brings us to the second methodological limitation, namely that a change in the work environment was not measured before a change in mental health outcome. Therefore, no conclusions could be drawn regarding a possible causal relationship and normal and reversed effects could not be disentangled. After all, a prerequisite for examining causality is that the change in exposure is measured before the actual change in the health outcome. ${ }^{28,29}$ To our knowledge, a study examining the relationship between changes in psychosocial work characteristics and subsequent changes in mental health has not been conducted yet.

To date, there is little information available on the time course of cause and effect between psychosocial work characteristics and mental health. ${ }^{30-32}$ In this respect, it might be questioned whether changes in job demands and control occur rather simultaneously with or before changes in mental health outcomes. In this study, two mental health outcomes were used that might react differently in the course of time. ${ }^{33}$ Need for recovery represents the short-term effects of a working day and has previously been associated with several work-related factors. $^{33-35}$ Moreover, previous prospective studies have shown that need for recovery is associated with the development of cardiovascular disease, ${ }^{36}$ subjective health complaints, ${ }^{34}$ and sickness absence. ${ }^{34}$ Prolonged fatigue in contrast represents long-term effects and has previously been associated with work schedules, ${ }^{37}$ psychosocial work characteristics, ${ }^{11}$ long-term illness, ${ }^{38}$ sick leave, ${ }^{39}$ and work disability. ${ }^{40}$

The net effect of changes in psychosocial work characteristics on mental health can only be determined by controlling for other factors that could disturb their actual relationship. When studying the effect of changes in job demands and control it is important to minimize selection bias, for example by ex- cluding employees with a long-term illness, and to rule out the effect of changes in other characteristics of the job, such as changes in job function, working time arrangements, and other work characteristics. ${ }^{23}$ In this respect, it must be noticed that studying changes reduces the possibility that any observed associations are spurious as a result of confounding by unobserved stable personality characteristics. $^{41}$

Elaborating on previous studies, $, 13,26$ this study examines the longitudinal association between changes in psychological job demands and decision latitude within 1 year of follow-up and changes in need for recovery and prolonged fatigue within the same period of time. The primary goal of this study, however, is to gain more insight into a possible causal relationship between psychosocial work characteristics and mental health by examining the effects of changes in psychological job demands and decision latitude on subsequent changes in need for recovery and prolonged fatigue, while controlling for potential confounding factors. A detailed insight into a possible causal relationship between psychosocial work characteristics and mental health is indispensable for designing effective prevention and intervention strategies. ${ }^{42}$

\section{Materials and Methods}

\section{Study Population}

This study is based on data from the Maastricht Cohort Study, a prospective study on fatigue at work, ${ }^{43}$ in which employees from 45 different companies (both blue-collar and white-collar jobs) were followed by means of self-administered questionnaires, which they received at 4-month intervals. Once a year, in May, employees received an extensive questionnaire with items on work and non-work-related factors, demographics, and health factors. Twice a year (in September and in January) employees received a short questionnaire, capturing mainly out- 


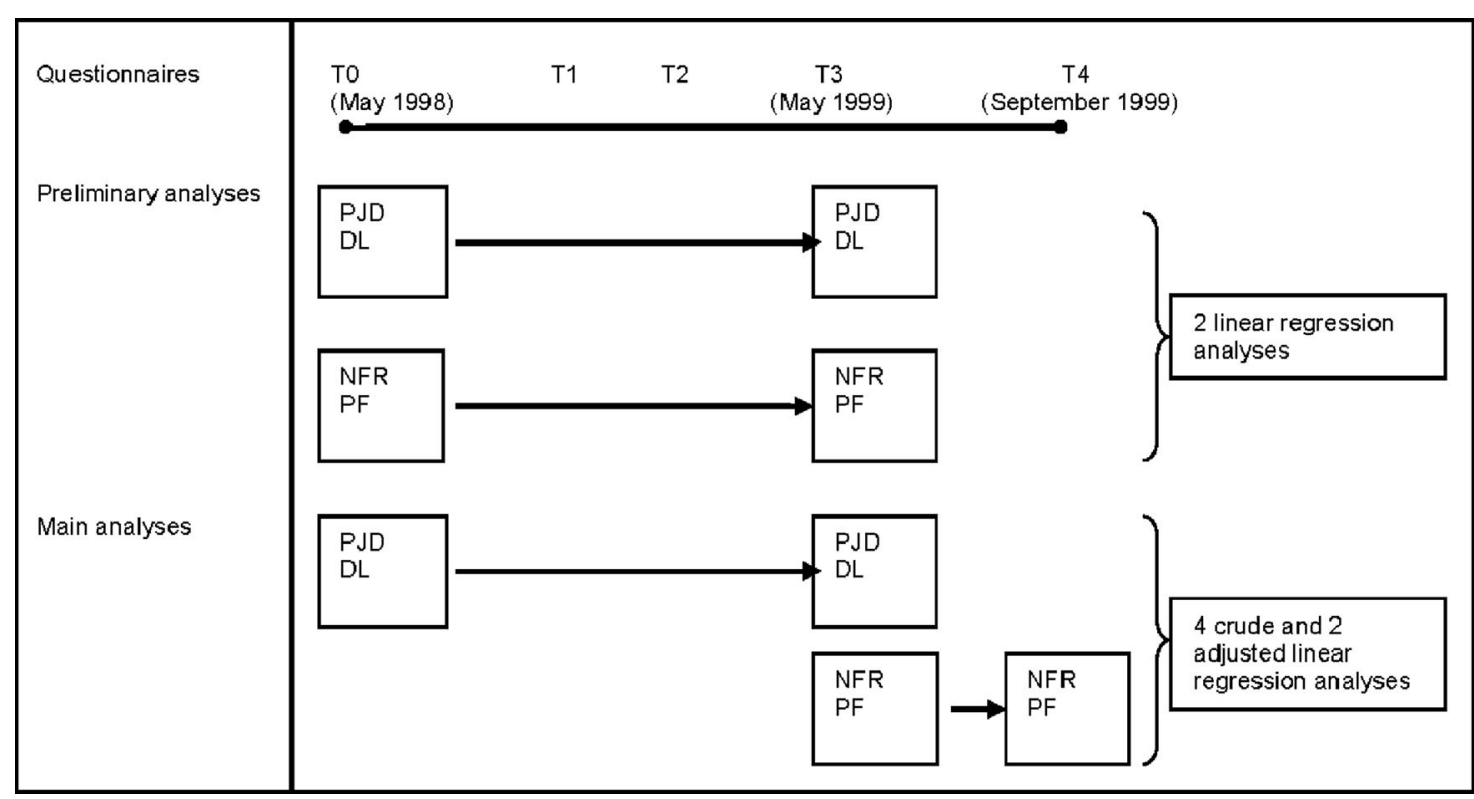

Fig. 1.Questionnaires, preliminary and main analysis in the present study $(n=2332)$ as part of the Maastricht Cohort Study. PJD indicates psychological job demands; DL, decision latitude; NFR, need for recovery; PF, prolonged fatigue.

\section{TABLE 1}

Baseline Characteristics of the Study Population and Frequencies of Changes in Psychosocial Work Characteristics From T0 to T3

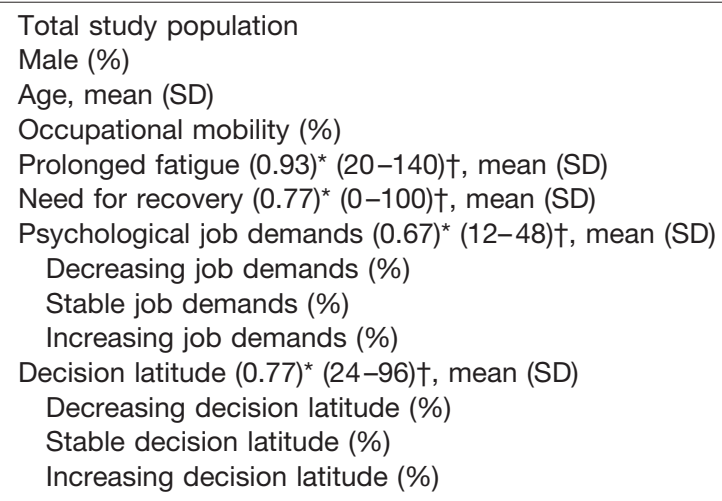

${ }^{*}$ Cronbach $\alpha$ in this study.

†Scale range.

come measures. In May 1998, the baseline questionnaire was sent out to 26,978 employees. Altogether, 12,161 employees completed and returned the baseline questionnaire (response rate of $45 \%$ ). Twenty-one questionnaires were excluded from analysis because of technical reasons. The baseline (T0) cohort thus consisted of 12,140 people. Employees who had completed the baseline questionnaire and at least one of the following two short questionnaires
(T1 and/or T2) received the 1-year follow-up questionnaire (T3) in May 1999 (response rate $79.5 \%, n=$ 9655). The consecutive short questionnaire (T4) was sent out in September 1999 (response rate $73.8 \%$, $n=8956$ ). Non-response analyses at baseline yielded no significant differences between respondents and non-respondents regarding demographic characteristics. Non-respondents were somewhat less likely to report fatigue complaints. A non- response analysis after 1 year of follow-up revealed that dropouts during the first year of follow-up were likely to report more fatigue complaints at baseline than were respondents. Further details on the sectors and trades represented in the Maastricht Cohort Study, the procedure, and the non-response has been reported elsewhere. ${ }^{37,43-45}$

Changes in psychosocial work characteristics (psychological job demands and decision latitude) were assessed between baseline (T0) and 1-year follow-up (T3; Fig. 1). As earlier analyses showed that changes in work schedule (day work vs shift work) and changes in working hours (part time vs full time) were prospectively related to changes in mental health, ${ }^{37,46}$ only employees involved in day work for at least $36 \mathrm{hrs} / \mathrm{wk}$ at both T0 and T3 were selected. Moreover, as a previous study ${ }^{46}$ showed that increasing working hours from 36 to $40 \mathrm{hrs} / \mathrm{wk}$ to $>40 \mathrm{hrs} / \mathrm{wk}$ increased the odds of developing selfreported health problems within 1 year of follow-up, employees who changed between working 36 to 40 $\mathrm{hrs} / \mathrm{wk}$ and $>40 \mathrm{hrs} / \mathrm{wk}$ were also excluded from this study. This selection resulted in 3830 employees who 
TABLE 2

Stepwise Regression Analyses for Changes in Psychosocial Work Characteristics Between T0 and T3 and Changes in Fatigue and Need for Recovery Between T0 and T3

\begin{tabular}{|c|c|c|c|c|}
\hline & \multicolumn{2}{|c|}{$\begin{array}{l}\Delta \text { Need for Recovery } \\
\quad(n=1973)\end{array}$} & \multicolumn{2}{|c|}{$\begin{array}{c}\Delta \text { Prolonged Fatigue } \\
\quad(n=1952)\end{array}$} \\
\hline & $\Delta R^{2}$ & $\beta$ & $\Delta R^{2}$ & $\boldsymbol{\beta}$ \\
\hline Occupational mobility T0-T3 & 0.001 & -0.010 & 0.001 & -0.022 \\
\hline Need for recovery/fatigue $\mathrm{TO}^{\mathrm{a}}$ & $0.006^{\star \star}$ & $-0.178^{\star \star \star}$ & $0.137^{\star \star \star}$ & $-0.427^{\star \star \star}$ \\
\hline Physical demands TO & $0.008^{\star}$ & $0.077^{\star \star}$ & $0.007^{*}$ & 0.041 \\
\hline Mental demands T0 & & $0.168^{\star \star \star}$ & & $0.095^{\star \star \star}$ \\
\hline Coworker social support T0 & & -0.022 & & -0.023 \\
\hline Supervisor social support T0 & & $-0.052^{*}$ & & -0.015 \\
\hline Psychological job demands TO & & $0.125^{\star \star \star}$ & & $0.097^{\star \star \star}$ \\
\hline Decision latitude TO & & -0.035 & & $-0.133^{\star \star \star}$ \\
\hline$\Delta$ Physical demands & $0.103^{\star \star \star}$ & $0.093^{\star \star \star}$ & $0.061^{\star \star \star}$ & $0.089^{\star \star \star}$ \\
\hline$\Delta$ Mental demands & & $0.238^{\star \star \star}$ & & $0.145^{\star \star \star}$ \\
\hline$\Delta$ Coworker social support & & -0.030 & & -0.023 \\
\hline$\Delta$ Supervisor social support & & $-0.075^{\star \star}$ & & $-0.072^{\star \star}$ \\
\hline$\Delta$ Psychological job demands & & $0.173^{\star \star \star}$ & & $0.108^{\star \star \star}$ \\
\hline$\Delta$ Decision latitude & & $-0.088^{\star \star}$ & & $-0.134^{\star \star \star}$ \\
\hline Total $R^{2}$ & $0.117^{\star \star \star}$ & & $0.206^{\star \star *}$ & \\
\hline Adjusted $R^{2}$ & 0.110 & & 0.200 & \\
\hline
\end{tabular}

${ }^{\star} P<0.05 ;{ }^{* \star} P<0.01 ;{ }^{* \star \star} P<0.001$.

${ }^{a}$ Need for recovery and prolonged fatigue at TO were added as covariates in the analysis with $\Delta$ need for recovery and $\Delta$ prolonged fatigue as outcome measures, respectively.

\section{TABLE 3}

Stepwise Regression Analyses for Changes in Psychosocial Work Characteristics Between T0 and T3 and a Subsequent Change in Fatigue and Need for Recovery Between T3 and T4

\begin{tabular}{|c|c|c|c|c|}
\hline & \multicolumn{2}{|c|}{$\Delta$ Need for Recovery } & \multicolumn{2}{|c|}{$\Delta$ Prolonged Fatigue } \\
\hline & $\Delta R^{2}$ & $\boldsymbol{\beta}$ & $\Delta R^{2}$ & $\boldsymbol{\beta}$ \\
\hline Occupational mobility T0-T3 & 0.001 & -0.030 & 0.001 & -0.043 \\
\hline Need for recovery/fatigue $\mathrm{T}^{\mathrm{a}}$ & $0.126^{\star \star \star}$ & $-0.384^{\star \star \star}$ & $0.074^{\star \star \star}$ & $-0.284^{\star \star \star}$ \\
\hline Psychological job demands T0 & $0.003^{\star \star}$ & $0.087^{\star \star}$ & 0.001 & $0.061^{\star}$ \\
\hline$\Delta$ Psychological job demands & $0.003^{*}$ & $0.063^{*}$ & $0.003^{*}$ & $0.057^{*}$ \\
\hline Total $R^{2}$ & $0.132^{\star \star \star}$ & & $0.079^{\star \star \star}$ & \\
\hline Adjusted $R^{2}$ & 0.130 & & 0.077 & \\
\hline$N$ & 1919 & & 1886 & \\
\hline Occupational mobility T0-T3 & 0.001 & -0.017 & 0.001 & -0.032 \\
\hline Need for recovery/fatigue $\mathrm{T}^{\mathrm{a}}$ & $0.125^{\star \star \star}$ & $-0.360^{\star \star \star}$ & $0.076^{\star \star \star}$ & $-0.292^{\star \star \star}$ \\
\hline Decision latitude T0 & 0.001 & $-0.070^{\star \star}$ & 0.002 & $-0.073^{\star \star}$ \\
\hline$\Delta$ Decision latitude & $0.005^{\star \star}$ & $-0.078^{\star \star}$ & $0.003^{*}$ & $-0.063^{\star}$ \\
\hline Total $R^{2}$ & $0.132^{\star \star *}$ & & $0.082^{\star \star \star}$ & \\
\hline Adjusted $R^{2}$ & 0.130 & & 0.080 & \\
\hline$N$ & 1972 & & 1938 & \\
\hline
\end{tabular}

${ }^{\star} P<0.05 ;{ }^{\star \star} P<0.01 ;{ }^{\star \star \star} P<0.001$.

${ }^{a}$ Need for recovery and prolonged fatigue at T3 were added as covariates in the analysis with $\Delta$ need for recovery and $\Delta$ prolonged fatigue as outcome measures, respectively.

were comparable with respect to working hours and in whom interdependency between changes in psychosocial work characteristics and changes in work time arrangements could be ruled out. From this selection, employees with multiple jobs at
T0 or T3 $(n=175)$ were also excluded, because information about the content and the characteristics of the other job was lacking. Moreover, employees who reported themselves to be absent from work because of illness or reported working under modified conditions related to former sickness absence (eg, fewer hours, modified tasks, or other functions) at the time of administering the T0 or T3 questionnaire $(n=448)$ were excluded from the analyses as they might have a distorted view of their work situation because of sickness absence. Finally, employees with a long-term illness at T0 or T3 $(n=875)$ were excluded from the analyses. These exclusions resulted in a final study population of 2332 employees. Baseline characteristics of the study population are presented in Table 1.

\section{Measures}

Psychosocial Work Characteristics. A validated Dutch version of the self-administered Job Content Questionnaire was used to measure psychological job demands, decision latitude, and social support at work. ${ }^{47,48}$ Psychological job demands were assessed by the sum of five items. Decision latitude consisted of two subscales: skill discretion (six items on the amount of skill used in the job) and decision authority (three items on the opportunity to make decisions concerning the job). For each item, the response options varied from "strongly disagree" to "strongly agree" on a four-point scale. Social support was measured with two scales (coworker support and supervisor support), each consisting of four items. For each scale the total score was calculated by adding the response scores to the items. Physical demands were assessed with a one-item question "would you consider your work to be physically demanding? (yes or no)." Mental demands were assessed using a one-item question "would you consider your work to be mentally demanding? (yes or no)." The latter two questions were derived from the Dutch questionnaire on Work and Health. ${ }^{49}$ Change scores of the work characteristics were calculated by subtracting the T0 score from the T3 score. For psychological job demands, a differential score above 


\section{TABLE 4}

Stepwise Regression Analyses for Changes in Psychosocial Work Characteristics Between T0 and T3 and a Subsequent Change in Fatigue and Need for Recovery Between T3 and T4

\begin{tabular}{|c|c|c|c|c|}
\hline & \multicolumn{2}{|c|}{$\begin{array}{l}\Delta \text { Need for Recovery } \\
\quad(n=1851)\end{array}$} & \multicolumn{2}{|c|}{$\begin{array}{c}\Delta \text { Prolonged Fatigue } \\
\quad(n=1821)\end{array}$} \\
\hline & $\Delta R^{2}$ & $\boldsymbol{\beta}$ & $\Delta R^{2}$ & $\boldsymbol{\beta}$ \\
\hline Occupational mobility T0-T3 & 0.001 & -0.019 & 0.001 & -0.026 \\
\hline Need for recovery/fatigue $\mathrm{T3}^{\mathrm{a}}$ & $0.127^{\star \star \star}$ & $-0.403^{\star \star \star}$ & $0.076^{\star \star \star}$ & $-0.324^{\star \star \star}$ \\
\hline Physical demands T0 & $0.012^{* \star *}$ & -0.015 & $0.011^{* *}$ & 0.009 \\
\hline Mental demands TO & & 0.014 & & 0.046 \\
\hline Coworker social support T0 & & -0.026 & & -0.025 \\
\hline Supervisor social support T0 & & $-0.072^{\star \star}$ & & $-0.101^{\star \star \star}$ \\
\hline Psychological job demands T0 & & $0.087^{\star \star}$ & & 0.034 \\
\hline Decision latitude TO & & $-0.072^{\star \star}$ & & -0.054 \\
\hline$\Delta$ Physical demands & $0.010^{\star *}$ & -0.022 & $0.009^{\star \star}$ & -0.010 \\
\hline$\Delta$ Mental demands & & -0.034 & & 0.005 \\
\hline$\Delta$ Coworker social support & & -0.013 & & -0.036 \\
\hline$\Delta$ Supervisor social support & & -0.008 & & $-0.056^{\star}$ \\
\hline$\Delta$ Psychological job demands & & $0.077^{\star \star}$ & & 0.049 \\
\hline$\Delta$ Decision latitude & & $-0.079^{\star \star}$ & & -0.051 \\
\hline Total $R^{2}$ & $0.150^{\star \star \star}$ & & $0.097^{\star \star \star}$ & \\
\hline Adjusted $R^{2}$ & 0.144 & & 0.090 & \\
\hline
\end{tabular}

${ }^{\star} P<0.001 ;{ }^{* \star} P<0.01 ;{ }^{* \star *} P<0.05$.

${ }^{a}$ Need for recovery and prolonged fatigue at T3 were added as covariates in the analysis with $\Delta$ need for recovery and $\Delta$ prolonged fatigue as outcome measures, respectively.

zero implied a negative change, ie, an increase in psychological job demands. For decision latitude, a differential score above zero implied a positive change, ie, an increase in decision latitude. Higher absolute differential scores implied more change, whereas differential scores approaching zero could be considered as approximately equaling a stable work situation. The frequency of changes in psychological job demands or decision latitude is also described in Table 1.

Mental Health Outcomes. The need for recovery from work was assessed using an 11-item scale from the Dutch Questionnaire on the Experience and Evaluation of Work (Dutch abbreviation, VBBA). ${ }^{35,50}$ The items represent short-term effects of a day of work (eg, "it is difficult for me to relax at the end of a working day"). Responses (no or yes) to the 11 items were summed up and standardized to generate a total score ranging from 0 to 100 . Higher scores indicate a higher need for recovery. Prolonged fatigue was measured with the Checklist Individual Strength (CIS), a 20-item question- naire developed to measure several aspects of prolonged fatigue. ${ }^{51}$ Whereas the need for recovery scale measures the recuperation period after 1 day of work and thus represents short-term effects, the CIS asks employees how they felt during the past 2 weeks. The CIS is a self-report instrument consisting of four subscales: subjective experience of fatigue (eight items, eg, "I feel tired"), concentration (five items, eg, "I have trouble concentrating"), motivation (four items, eg, "I feel no desire to do anything"), and physical activity level (three items, eg, "I don't do much during the day"). The responses to each statement are scored on seven-point Likert scales ranging from "yes, that is true," to "no, that is not true." Higher scores indicate a higher degree of fatigue, lower levels of concentration, reduced motivation, or less activity. A composite CIS-total score, ranging from 20 to 140 , was constructed by adding the individual's scores on the four factors. Change scores on the need for recovery scale and the fatigue scale were calculated by subtracting the
T0 score from the T3 score (preliminary analyses) or by subtracting the T3 score from the T4 score (main analyses). A differential score above zero implied a negative change, ie, an increase in need for recovery or fatigue.

Occupational Mobility. Within the first year of follow-up (between T0 and T3), employees were asked every 4 months whether they changed their job function in the past 4 months. These scores were combined into the variable occupational mobility, which was defined as a change in job function between $\mathrm{T} 0$ and $\mathrm{T} 3$ and which was included as a confounder in the model. As such, it was possible to study the health effects of changes in psychosocial work characteristics independent of changes in job function.

\section{Statistical Analysis}

The analyses in this study can be divided into preliminary and main analyses (Fig. 1). In the preliminary analyses, the longitudinal relationship between changes in psychological job demands and decision latitude within 1 year of follow-up and changes in mental health outcomes within the same period of time was examined (secondary goal of the study). In the main analyses, a possible causal relationship was examined between changes in psychological job demands and decision latitude and subsequent changes in need for recovery and prolonged fatigue after 4 months (main goal of the study).

In the preliminary analyses, the longitudinal relationship between a change in psychological job demands and decision latitude between $\mathrm{T} 0$ and $\mathrm{T} 3$ and a change in need for recovery and prolonged fatigue between T0 and T3 was examined using two stepwise linear regression analyses. In the first step of the regression analyses, we controlled for occupational mobility. The T0 score of the dependent variable involved was added in the second step. The third step of the regression analysis was to control for the work characteristics at T0. Finally, changes 
in other work characteristics between $\mathrm{T} 0$ and $\mathrm{T} 3$ were controlled for in the fourth step.

In the main analyses, four linear regression analyses were performed to examine the effects of changes in psychological job demands and decision latitude between $\mathrm{T} 0$ and $\mathrm{T} 3$ on subsequent changes in need for recovery and prolonged fatigue between T3 and T4. In this case, the change in work characteristics occurs before the change in need for recovery or fatigue and a possible causal relationship might be detected. To gain insight into a rather crude effect, two linear regression analyses were performed to study the relationship between changes in psychological job demands between T0 and T3 and changes in need for recovery and prolonged fatigue between T3 and T4, while stepwise controlling for occupational mobility (step 1), the T3 value of the respective outcome variable (step 2), and the baseline psychological job demands (step 3). Two analogous linear regression analyses were performed for the change in decision latitude between T0 and T3. Finally, to gain insight into the net effect of changes in psychological job demands and decision latitude, two linear regression analyses were performed, while stepwise controlling for occupational mobility (step 1), the $\mathrm{T} 3$ value of the respective outcome variable (step 2), baseline work characteristics (step 3), and changes in other work characteristics between T0 and T3 (step 4). By controlling for the previous measurement of both the dependent as well as the independent variables in the regression analyses, we were able to control for regression to the mean, floor and ceiling effects, which are the most important artifacts of the statistical analysis of change scores. ${ }^{52-54}$ The focus of all the analyses in this study is the effect of the change in psychological job and the change in decision latitude in the last step of the analyses. All analyses were per- formed using the SPSS 13.0 statistical packages (Chicago, IL). ${ }^{55}$

\section{Results}

Table 1 shows that a rather extensive part of the study population experienced a change in psychological job demands and decision latitude in the first year of follow-up. A decrease in psychological job demands occurred in $44 \%$ of the study population whereas $40.8 \%$ experienced an increase in demands between $\mathrm{T} 0$ and T3. Almost $46 \%$ encountered a decrease in decision latitude whereas about $41 \%$ experienced an increase in decision latitude.

Table 2 presents the results of the preliminary analyses, ie, two stepwise regression analyses for the longitudinal relationship between changes in psychological job demands and decision latitude and changes in fatigue and need for recovery in the same follow-up period. The standardized $\beta$ values of the end model are presented. Results show that increasing psychological job demands are significantly associated with increases in need for recovery $(\beta=0.173)$ and prolonged fatigue $(\beta=0.108)$. An increase in decision latitude is significantly associated with lower levels of need for recovery $(\beta=-0.088)$ and with less prolonged fatigue $(\beta=-0.134)$.

The results from the main analyses of this study are presented in Tables 3 and 4 . Table 3 presents the effects of changes in psychological job demands and decision latitude on subsequent changes in need for recovery and prolonged fatigue without correcting for other work characteristics. After correction for occupational mobility, fatigue at $\mathrm{T} 3$ and baseline psychological job demands, increasing psychological job demands are a significant predictor of a subsequent increase in the level of need for recovery $(\beta=0.063)$ and prolonged fatigue $(\beta=0.057)$. Moreover, Table 3 shows that an increase in decision latitude predicts a subsequent decrease in need for recovery $(\beta=-0.078)$ and prolonged fatigue $(\beta=-0.063)$.

Table 4 presents the effects of changes in psychological job demands and decision latitude on subsequent changes in need for recovery and prolonged fatigue, adjusted for other work characteristics. Results show that changes in psychological job demands and decision latitude have no significant effect on subsequent changes in the level of prolonged fatigue. The corresponding $P$ values are 0.065 for psychological job demands and 0.060 for decision latitude. Increasing psychological job demands are a significant predictor of a subsequent increase in the need for recovery $(\beta=0.077)$. An increase in decision latitude is a significant predictor of subsequent decreasing levels of need for recovery ( $\beta=-0.060)$.

\section{Discussion}

This study confirms and extends the results of earlier studies, which have indicated that changes in psychosocial work characteristics are associated with employees' health and well-being. ${ }^{8,13,56}$ The results of this study show a significant longitudinal relationship between changes in psychological job demands and decision latitude within 1 year of follow-up and changes in need for recovery and prolonged fatigue within the same period of time. These results were in line with previous research. ${ }^{13,26}$ Nevertheless, it was still not possible to fully disentangle a possible cause and effect relationship. In this study, we therefore tried to extend previous research in this field by measuring changes in mental health outcomes within a relatively short time span (4 months) after a change in psychological job demands or decision latitude. When changes in other work characteristics were not controlled for, a significant effect was found for psychological job demands and decision latitude on both the subsequent need for recovery and subsequent prolonged fatigue. When controlling for changes in other work characteris- 
tics, increasing psychological job demands were a significant predictor of a subsequent increase in need for recovery, whereas an increase in decision latitude significantly predicted a decrease in subsequent levels of need for recovery. After including other work characteristics as confounders in the model, the effects of psychological job demands and decision latitude on subsequent levels of prolonged fatigue were no longer significant. All relationships were in the expected direction.

The results of this study suggest that the impact of changes in psychological job demands and decision latitude depends rather strongly on the time course of cause and effect between psychosocial work characteristics and mental health outcomes. Frese and Zapf ${ }^{30}$ describe two models of how a stressor can affect ill health in the course of time. First, in the exposure time model, the incidence of ill health increases with the duration of exposure to a stressor. According to the stress reaction model, a specific type of the exposure time model, the impact of a stressor increases and leads to psychological dysfunction after a certain time. Once the stressor is removed, there is an improvement in psychological functioning. In the second model ill health can be considered a rather immediate response to the shock of being exposed to a stressor, and has the tendency to reduce over time. This model is also known as the initial impact model. As changes in mental health outcomes were measured within a relatively short period of time (4 months) after a change in psychological job demands and decision latitude, the results of this study might be an indication of a rather immediate effect of changes in psychosocial work characteristics on subsequent changes in need for recovery and prolonged fatigue, in other words, an initial impact. Nevertheless, it can also be questioned whether the impact was actually initially being measured in this study. Despite frequent sampling in the
Maastricht cohort study, items on psychosocial work characteristics were only measured in the questionnaires that were sent out annually. Consequently, the change in psychological job demands and decision latitude was measured over the 1-year period from baseline (T0) to 1-year follow-up (T3). As such, we do not exactly know when the change in job demands and decision latitude took place. Therefore, according to the initial impact model, it is possible that the initial effects had already reduced at the time the outcomes were measured and that only a residual effect, that is an underestimation of the actual effect, was measured. Future research might profit from using shorter time intervals for measuring changes in psychosocial work characteristics. On the other hand, it is also possible that, in line with the stress reaction model, the impact of a change in, for example, psychological job demands has not reached its peak yet. Therefore, future research might also benefit from using different time lags for measuring mental health outcomes. Nevertheless, we do think that time lags should not be too long, as work characteristics can change again within this period.

A frequent flaw in previous research on psychosocial work characteristics is that it often ignores the rather dynamic nature of certain work characteristics. For example, job demands are studied at a particular point in time, whereas health outcomes are studied 1 year afterwards. As such, the fact that job demands seem to change rather frequently over time is often neglected. Hence, when comparing employees with low demands with employees with high demands at a particular time and examining the health of these two groups 1 year afterwards, a serious misclassification might occur, because a rather extensive part of the total population already experienced a change in demands within this year of follow-up. As in this study a rather dynamic work envi- ronment was observed, studying individual changes in work characteristics in relation to individual changes in mental health outcomes over time is essential and allows us to gain more insight into the causal relationship between work characteristics and health.

Besides the fact that changes in exposure need to be measured before a change in the outcome, the existence of a possible causal relationship cannot be established without ruling out other plausible explanations. In this study, several attempts have been made to minimize the influence of selection bias and possible confounding factors.

First, selection bias was minimized by selecting a rather homogenous study population. ${ }^{23}$ For example, by selecting only employees involved in stable day work for at least $36 \mathrm{hrs} / \mathrm{wk}$ at both $\mathrm{T} 0$ and $\mathrm{T} 3$, we were able to study the effects of changes in psychological job demands and decision latitude independently of changes in work schedule or working hours. Although this increases the internal validity of the study it may limit the ability to generalize the findings. Additionally, some exclusion criteria could also have resulted in over-control and hence in an underestimation of the actual effects. Despite our attempts to minimize selection bias, it is rather unlikely that we were able to eliminate all selection effects. In this respect, it can be argued that our first measurement is not a true baseline measurement. The employees in this study were already in the middle of an ongoing process with regard to both psychosocial work characteristics as well as health. The preexisting work environment and changes that have already taken place in the past might have already influenced the health of the respondents before our actual baseline measurement. For example, employees experiencing high psychological job demands might have undertaken some kind of action to reduce the demands (eg, working fewer hours) and the hazards that 
might bring to their health. In other words, a selection bias might have already occurred before our first measurement.

Second, studying individual changes in exposure in relation to individual changes in health over time cancels out the possibility that observed associations are due to confounding by unobserved stable characteristics. ${ }^{41}$ If change scores are computed by subtracting two measurements of the same variable, then both measurements are affected equally by stable variables and relationships between intra-individual changes are not affected. $^{57}$

Third, in this study, the influence of possible confounding factors was minimized. In the analyses, the baseline level of both the dependent as well as the independent variables was controlled for. Although the highly significant inverse relationship between, eg, baseline prolonged fatigue and the change in prolonged fatigue seems to indicate regression toward the mean, this possibility was largely ruled out in this study. As change scores of the outcome variables were used while correcting for the initial value of the outcome variable, it was possible to control for regression to the mean and for floor and ceiling effects. ${ }^{52-54}$ Additionally, we controlled for changes in other work characteristics. Compared with a cruder model, these adjustments resulted in smaller $\beta$ values for prolonged fatigue, and the results for prolonged fatigue became insignificant. Nevertheless, the $\beta$ values were still in the expected direction and the corresponding $P$ values (0.065 for psychological job demands and 0.060 for decision latitude) showed that the relationship was borderline significant. These results might be an indication of the fact that changes in psychosocial work characteristics coincide with one another and that it is rather difficult to study changes in psychological job demands irrespective of changes in, for example, social support. We further examined whether changes in health behaviors, such as smoking, drinking, physical activity, and body mass index caused a relevant change in the regression coefficient, but as they did not, they were left out of the analyses.

Although this study showed that changes in psychological job demands and decision latitude were often statistically significant, in general the observed effects were rather small. Therefore, clinical relevance might be questioned. Some methodological features of this study might have had an impact on the strength of the effects found. First, as change scores in psychological job demands and decision latitude were measured in this study, it is possible that even a small change has resulted in increasing levels of, for example, prolonged fatigue. Increasing the contrast in the independent variables through, for example, changes to the highest tertile of the scale would probably have resulted in a larger effect and clinically more relevant changes in, for example, prolonged fatigue. Second, linear data analysis might have resulted in an underestimation of the true effect of changes in work characteristics on changes in mental health outcomes. ${ }^{32}$ In this study, the change score of, for example, psychological job demands contained both positive as well as negative changes on the job demands scale, thereby automatically assuming that increases in demands would have the same impact as decreases in demands, only the direction of the association should be reversed. ${ }^{32}$ It is, however, possible that the strength of the effect of increasing demands is not the same as the strength of the effect of decreasing demands and that separate analyses for increasing and decreasing demands would induce a larger contrast, perhaps resulting in higher or lower $\beta$ values.

Third, the baseline response of $45 \%$ and the loss of follow-up over time might raise the question of selective participation of employees and selective dropout, which may have biased the findings in this study. Non-response analyses ${ }^{43}$ revealed that fatigue complaints were lower among nonrespondents at the baseline measurement, but higher during follow-up compared with the respondents. This selective dropout may have resulted in an underestimation of the findings in this study.

Fourth, both psychosocial work characteristics as well as mental health outcomes were measured by means of questionnaire data. The findings could thus reflect common method variance, which may lead to an overestimation of the strength of the association between the psychosocial work characteristics and mental health. Including some objective measures of the work environment and health outcomes as well might be interesting for future research.

The results of this study clearly show that changes in psychosocial work characteristics are prospectively related to statistically significant changes in need for recovery and prolonged fatigue. In this study, the dynamic nature of the work characteristics was thoroughly taken into account, selection bias was restrained, and the influence of possible confounding factors was minimized. Moreover, changes in exposure were measured before changes in mental health outcomes. Therefore, these findings support a possible causal relationship between changes in psychosocial work characteristics and changes in mental health outcomes. Given the considerable impact of changes in psychological job demands and decision latitude on the employee and the high frequency in which these changes can occur, these findings underline the need for interventions addressing psychosocial work characteristics.

\section{References}

1. Peter R, Siegrist J. Psychosocial work environment and the risk of coronary heart disease. Int Arch Occup Environ Health. 2000;73(Suppl):S41-S45.

2. Schnall PL, Landsbergis PA, Baker D. Job 
strain and cardiovascular-disease. Annu Rev Public Health. 1994;15:381-411.

3. Guimont C, Brisson C, Dagenais GR, et al. Effects of job strain on blood pressure: a prospective study of male and female white-collar workers. Am J Public Health. 2006;96:1436-1443.

4. Buckle P. Upper limb disorders and work: the importance of physical and psychosocial factors. J Psychosom Res. 1997;43:17-25.

5. Davis KG, Heaney CA. The relationship between psychosocial work characteristics and low back pain: underlying methodological issues. Clin Biomech. 2000; 15:389-406.

6. Clays E, De Bacquer D, Leynen F, Kornitzer M, Kittel F, De Backer G. The impact of psychosocial factors on low back pain: longitudinal results from the Belstress study. Spine. 2007;32:262-268.

7. Niedhammer I, Goldberg M, Leclerc A, Bugel I, David S. Psychosocial factors at work and subsequent depressive symptoms in the Gazel cohort. Scand J Work Environ Health. 1998;24:197-205.

8. Stansfeld SA, Fuhrer R, Shipley MJ, Marmot MG. Work characteristics predict psychiatric disorder: prospective results from the Whitehall II Study. Occup Environ Med. 1999;56:302-307.

9. Sanne B, Mykletun A, Dahl AA, Moen BE, Tell GS. Testing the Job Demand-ControlSupport model with anxiety and depression as outcomes: the Hordaland Health Study. Occup Med. 2005;55:463-473.

10. Stansfeld S, Candy B. Psychosocial work environment and mental health - a metaanalytic review. Scand J Work Environ Health. 2006;32:443-462.

11. Bültmann U, Kant I, Van den Brandt PA, Kasl SV. Psychosocial work characteristics as risk factors for the onset of fatigue and psychological distress: prospective results from the Maastricht Cohort Study. Psychol Med. 2002;32:333-345.

12. Bültmann U, Kant IJ, Schroer CAP, Kasl $\mathrm{SV}$. The relationship between psychosocial work characteristics and fatigue and psychological distress. Int Arch Occup Environ Health. 2002;75:259-266.

13. Janssen N, Nijhuis FJ. Associations between positive changes in perceived work characteristics and changes in fatigue. J Occup Environ Med. 2004;46:866875.

14. Borg V, Kristensen TS, Burr H. Work environment and changes in self-rated health: a five year follow-up study. Stress Med. 2000;16:37-47.

15. Niedhammer I, Chea M. Psychosocial factors at work and self reported health: comparative results of cross sectional and prospective analyses of the French GA-
ZEL cohort. Occup Environ Med. 2003; 60:509-515.

16. Rahkonen O, Laaksonen M, Martikainen P, Roos E, Lahelma E. Job control, job demands, or social class? The impact of working conditions on the relation between social class and health. $J$ Epidemiol Community Health. 2006;60:50-54.

17. Niedhammer I, Bugel I, Goldberg M, Leclerc A, Gueguen A. Psychosocial factors at work and sickness absence in the Gazel cohort: a prospective study. Occup Environ Med. 1998;55:735-741.

18. North FM, Syme SL, Feeney A, Shipley M, Marmot M. Psychosocial work environment and sickness absence among British civil servants: the Whitehall II Study. Am J Public Health. 1996;86:332-340.

19. Brisson C, Larocque B, Moisan J, Vezina M, Dagenais GR. Psychosocial factors at work, smoking, sedentary behavior, and body mass index: a prevalence study among 6995 white collar workers. J Occup Environ Med. 2000;42:40-46.

20. Hellerstedt WL, Jeffery RW. The association of job strain and health behaviors in men and women. Int J Epidemiol. 1997; 26:575-583.

21. Tsutsumi A, Kayaba K, Yoshimura M, et al. Association between job characteristics and health behaviors in Japanese rural workers. Int J Behav Med. 2003;10:125142 .

22. Karasek RA. Job demands, job decision latitude, and mental strain: implications for job redesign. Adm Sci Q. 1979;24:285-308.

23. de Jonge J. A critical examination of the demand-control-support model from a work psychological perspective. Int $J$ Stress Manag. 1997;4:235-258.

24. de Lange AH, Taris TW, Kompier MA, Houtman IL, Bongers PM. "The very best of the millennium": longitudinal research and the demand-control-(support) model. J Occup Health Psychol. 2003;8: 282-305.

25. Van der Doef M, Maes S. The Job Demand-Control(-Support) model and psychological well-being: a review of 20 years of empirical research. Work Stress. 1999;13:87-114.

26. Gelsema TI, van der Doef M, Maes S, Janssen M, Akerboom S, Verhoeven C. A longitudinal study of job stress in the nursing profession: causes and consequences. J Nurs Manag. 2006;14:289-299.

27. Godin I, Kittel F, Coppieters Y, Siegrist J. A prospective study of cumulative job stress in relation to mental health. BMC Public Health. 2005;5:67.

28. Lilienfeld DE, Stolley PD. Foundations of Epidemiology. 3rd ed. New York: Oxford University Press; 1994.

29. Rothman KJ, Greenland S. Causation and causal inference in epidemiology. Am J Public Health. 2005;95(Suppl 1):S144-S150.

30. Frese M, Zapf D. Methodological issues in the study of work stress: objective vs subjective measurement of work stress and the question of longitudinal studies. In: Cooper CL, Payne R, eds. Causes, Coping and Consequences of Stress at Work. Chichester, UK: Wiley;1988:375-411.

31. Taris TW, Kompier M. Challenges in longitudinal designs in occupational health psychology. Scand J Work Environ Health. 2003;29:1-4.

32. Zapf D, Dormann C, Frese M. Longitudinal studies in organizational stress research: a review of the literature with reference to methodological issues. $J O C$ cup Health Psychol. 1996;1:145-169.

33. Jansen NWH, Kant I, van den Brandt PA. Need for recovery in the working population: description and associations with fatigue and psychological distress. Int J Behav Med. 2002;9:322-340.

34. Sluiter JK, de Croon EM, Meijman TF, Frings-Dresen MHW. Need for recovery from work related fatigue and its role in the development and prediction of subjective health complaints. Occup Environ Med. 2003;60:62-70.

35. Van Veldhoven M, Broersen S. Measurement quality and validity of the "need for recovery scale". Occup Environ Med. 2003;60(Suppl 1):i3-i9.

36. Van Amelsvoort LGPM, Kant IJ, Bültmann U, Swaen GMH. Need for recovery after work and the subsequent risk of cardiovascular disease in a working population. Occup Environ Med. 2003; 60(Suppl 1):i83-i87.

37. Jansen NWH, van Amelsvoort LGPM, Kristensen TS, van den Brandt PA, Kant I. Work schedules and fatigue: a prospective cohort study. Occup Environ Med. 2003;60(Suppl 1):i47-i53.

38. Franssen PML, Bultmann U, Kant I, van Amelsvoort LGPM. The association between chronic diseases and fatigue in the working population. J Psychosom Res. 2003;54:339-344.

39. Janssen N, Kant IJ, Swaen GMH, Janssen PPM, Schroer CAP. Fatigue as a predictor of sickness absence: results from the Maastricht cohort study on fatigue at work. Occup Environ Med. 2003;60:71-76.

40. van Amelsvoort LGPM, Kant IJ, Beurskens AJHM, Schroer CAP, Swaen GMH. Fatigue as a predictor of work disability. Occup Environ Med. 2002;59:712-713.

41. Head J, Kivimaki M, Martikainen P, Vahtera J, Ferrie JE, Marmot MG. Influence of change in psychosocial work characteristics on sickness absence: the Whitehall II Study. J Epidemiol Community Health. 2006;60:55-61. 
42. Reynolds S. Psychological well-being at work: is prevention better than cure? J Psychosom Res. 1997;43:93-102.

43. Kant I, Bültmann U, Schroer KAP, Beurskens AJHM, Van Amelsvoort LGPM, Swaen GMH. An epidemiological approach to study fatigue in the working population: the Maastricht Cohort Study. Occup Environ Med. 2003;60(Suppl 1): i32-i39.

44. Bültmann U, Kant I, Kasl SV, Beurskens AJ, van den Brandt PA. Fatigue and psychological distress in the working population: psychometrics, prevalence, and correlates. J Psychosom Res. 2002; 52:445-452.

45. Kant I, Beurskens AJ, Schroër C, Nijhuis F, van Schayck CP. De Maastrichtse Cohort Studie naar langdurige psychische vermoeidheid in de arbeidssituatie [The Maastricht Cohort Study of prolonged fatigue at work]. $T B V .2000 ; 8: 226-232$.

46. De Raeve L, Jansen NWH, Kant I. Health effects of transitions in work schedule, workhours and overtime in a prospective cohort study. Scand J Work Environ Health. 2007;33:105-113.
47. Karasek R, Brisson C, Kawakami N, Houtman I, Bongers P, Amick B. The Job Content Questionnaire (JCQ): an instrument for internationally comparative assessments of psychosocial job characteristics. J Occup Health Psychol. 1998;3:322-355.

48. Karasek RA. The Job Content Questionnaire and User's Guide (version 1.1). Los Angeles, CA: Department of Industrial and Systems Engineering, University of Southern California; 1985.

49. Grundemann RMW, Smulders PGW, de Winter CR. Vragenlijst Arbeid en Gezondheid (VAG) [Questionnaire on Work and Health]. Lisse: Swets \& Zeitlinger; 1993.

50. Van Veldhoven M, Meijman TF. Het meten van psychosociale arbeidsbelasting met een vragenlijst: de vragenlijst beleving en beoordeling van de arbeid (VBBA) [The Measurement of Psychosocial Job Demands with a Questionnaire (VBBA)]. Amsterdam, NL: NIA-TNO; 1994.

51. Vercoulen JH, Swanink CM, Fennis JF, Galama JM, van der Meer JW, Bleijenberg G. Dimensional assessment of chronic fatigue syndrome. J Psychosom Res. 1994;38:383-392.

52. Taris TW. A Primer in Longitudinal Data-Analysis. London, UK: Sage; 2000.

53. Twisk JWR. Applied Longitudinal Data Analysis for Epidemiology. A Practical Guide. Cambridge, UK: Cambridge University Press; 2003.

54. Rogosa DR. Myths and methods: myths about longitudinal research plus supplemental questions. In: Gottman JM, ed. The Analysis of Change. Mahwah, NJ: Lawrence Erlbaum;1996:3-66.

55. SPSS. SPSS Base 13.0. Chicago, IL: SPSS Inc.; 2005.

56. De Jonge J, Le Blanc PM, Schaufeli WB, van der Linden S. Verandering in werkkenmerken in relatie tot verandering in burnout en arbeidstevredenheid [Changes in job characteristics as related to changes in burnout and job satisfaction]. Gedrag en Organisatie. 1998;11:121-134.

57. Rodgers WL. Comparison of alternative approaches to the simple causal models from panel data. In: Kasprzyk D, Duncan G, Kalton G, Singh MP, eds. Panel Surveys. New York: Wiley;1989:432-456. 